\title{
Universiteit
}

Leiden

The Netherlands

\section{The effect of urban nature exposure on mental health-a case study of} Guangzhou

Liu, H.X.; Ren, H.; Remme, R.P.; Nong, H.F.; Sui, C.H.

\section{Citation}

Liu, H. X., Ren, H., Remme, R. P., Nong, H. F., \& Sui, C. H. (2021). The effect of urban nature exposure on mental health-a case study of Guangzhou. Journal Of Cleaner Production, 304. doi:10.1016/j.jclepro.2021.127100

Version: $\quad$ Publisher's Version

License: $\quad$ Licensed under Article 25fa Copyright Act/Law (Amendment Taverne)

Downloaded from: https://hdl.handle.net/1887/3214380

Note: To cite this publication please use the final published version (if applicable). 


\title{
The effect of urban nature exposure on mental health-a case study of Guangzhou
}

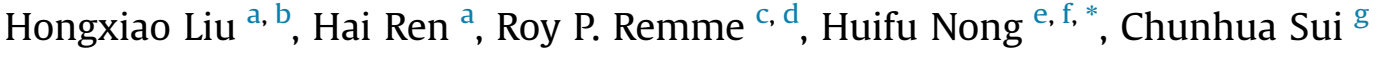 \\ ${ }^{a}$ CAS Engineering Laboratory for Vegetation Ecosystem Restoration on Islands and Coastal Zones, South China Botanical Garden, Chinese Academy of \\ Sciences, Guangzhou, 510650, China \\ ${ }^{\mathrm{b}}$ Southern Marine Science and Engineering Guangdong Laboratory (Guangzhou), Guangzhou, 511458, China \\ c Institute of Environmental Sciences CML, Leiden University, Einsteinweg 2, 2333, CC, Leiden, the Netherlands \\ d Natural Capital Project, Dept. of Biology and Woods Institute for the Environment, Stanford University, Stanford, CA, 94305, USA \\ e School of Finance and Investment, Guangdong University of Finance, Guangzhou, 510521, China \\ ${ }^{\mathrm{f}}$ Dept. of Economics, Sun Yat-sen University, Guangzhou, 510275, China \\ ${ }^{\mathrm{g}}$ Tourism Department of Shaoguan University, Shaoguan, 512005, China
}

\section{A R T I C L E I N F O}

\section{Article history:}

Received 14 July 2020

Received in revised form

10 March 2021

Accepted 10 April 2021

Available online 14 April 2021

Handling editor: Bin Chen

\section{Keywords:}

Greenspace

Subjective well-being

Blue space

Mental health

Built environment

Public health

\begin{abstract}
A B S T R A C T
There is considerable evidence concerning the salutary effects of nature on mental health in developed countries. However, these benefits are less examined and recognized in Chinese cities where $11 \%-15 \%$ of the population are facing increasing mental health issues. To provide more comprehensive evidence concerning nature's benefits on multiple components of mental health in Chinese cities, we address two poorly resolved questions: i) does exposure to urban park and blue space have equivalent associations with multiple components of mental health? ii) do these associations vary across gender and socioeconomic groups? We conducted two waves of cross-sectional surveys in Guangzhou and investigated 1,274 respondents' (933 from online survey and 341 from face-to-face survey) depression risk and four aspects of subjective well-being (SWB) including life satisfaction, worthwhileness, happy yesterday, and anxious yesterday. The results suggest that both park and blue space exposure mitigate depression risk and negative affect well-being, however their associations vary with evaluative, eudemonic, and positive affect well-being. Achieving SWB across all its components needs access to both park and blue space. One-hectare increase in accessible water is associated with an improvement up to $0.45 \%$ anxious yesterday scores indicating blue space a potential public health resource. We observed a clear genderand socioeconomic differences: nearby nature has stronger protective effects for female, lower educated and low-to-median income population groups than their counterpart. Although the heterogeneities need to be confirmed in other urban settings, our findings suggest that effective actions need to consider gender- and socioeconomic differences to target potential beneficiaries and maximize the returns of investments and policy interventions.
\end{abstract}

() 2021 Elsevier Ltd. All rights reserved.

\section{Introduction}

The Report on National Mental Health Development in China (2017-2018) revealed that $11 \%-15 \%$ of the Chinese population have mild to moderate mental health conditions and $2 \%-3 \%$ have moderate to serious mental health conditions (Fu and Zhang, 2019).

\footnotetext{
* Corresponding author. Guangdong University of Finance, No. 527, Yingfu Road, Tianhe District, Guangzhou, 510521, PR China.

E-mail addresses: liuhx@scbg.ac.cn (H. Liu), renhai@scbg.ac.cn (H. Ren), r.p. remme@cml.leidenuniv.nl (R.P. Remme), nonghf3@mail.sysu.edu.cn (H. Nong), 916942159@qq.com (C. Sui).
}

A growing body of empirical evidence in developed countries has revealed the benefits of nature exposure to human mental health through mitigating environmental stressors such as air pollution and noise (Frumkin et al., 2017), restoring attention, reducing stress (Bratman et al., 2012), providing a pleasant venue for social interactions, and fostering physical activities (Hartig et al., 2014). However, there are only few empirical evidence available concerning Chinese cities (Liu et al., 2020). China's population grew to 1.4 billion in 2018, and 59\% resided in urban settlements (United Nations, 2019). Clearly, empirical studies on Chinese cities, such as rapidly urbanized Guangzhou-the city under study-are needed to provide insights for effective interventions given the 
notable differences in culture, economic development, life style, urban form, etc., between Chinese and western cities (Amano et al., 2018).

Mental health is a multi-dimensional measure and it encompasses the absence of common mental disorders and a complete state of subjective well-being (SWB; Keyes, 2006). Building on long-standing debates, there is growing research and policy consensus that there are four components of SWB: a) evaluative well-being, how well individuals think their life is going overall, b) eudaimonic well-being, how worthwhile individuals think their behaviors are, c) positive, and d) negative affect well-being, the emotions of pleasure (e.g., happiness) and pain (e.g., anxiety) individuals regularly experience (Kahneman et al., 1999; O'Donnell et al., 2014; White et al., 2017). To date, evidence concerning nature and mental health remains fragmented as most studies focused either on specific mental illness or a specific aspect of SWB. For example, Callaghan et al. (2020)'s review found only 8 out of 25 studies measured two or more mental health aspects, among which four studies measured more than one mental illness, while neglecting SWB dimensions. The other four measured more than one dimension of SWB, but overlooking the mental illness dimension. A comprehensive and precise understanding of nature's impacts on multiple aspects of mental health is lacking. However, this is important for policymakers since, for example, the benefit of promoting positive mental health is different from reducing mental illness (Gascon et al., 2015).

In this study, we simultaneously measured MHI-5 (Mental Health Inventory), a marker of psychological ill-health (Thorsen et al., 2013) and four aspects of SWB including evaluative (life satisfaction), eudaimonic (worthwhileness), negative and positive affect well-being (happy yesterday and anxious yesterday) to provide comprehensive evidence on nature's association with multiple components of mental health in Guangzhou, China.

Urban greenspace includes parks, street trees, residential greenspace, vegetated sports field, urban forest etc. Overall greenness measured by Normalized Difference Vegetation Index (NDVI) and public greenspaces are most studied (Callaghan et al., 2020). Urban parks, which often consist of vegetated areas, are drawing increasing attention due to their strong implications for public policy (Wood et al., 2017). Cumulative opportunity measures (amount/number of parks within certain spatial area) or proximity measures (the access to nearest park) are often measured as exposure metrics (Ekkel and de Vries, 2017; Wood et al., 2017). One element that is rarely studied is the size of parks. Large parks are reported to associate with higher physical activity, one pathway that mediates the association between nature and mental health (Zhang et al., 2019). However, park size is often addressed by setting a minimum area threshold when calculating proximity indicators in previous research (e.g., analyzing the effect of parks larger than 1 ha on mental health) (Ekkel and de Vries, 2017). Whether park size matters in improving mental health requires further exploration, as the answer has consequences for spatial planning. For example, would it be more advantageous for mental health to build one big park or rather two smaller parks that are accessible to more people?

Compared with greenspace, the salutary effects of blue space are less studied, with mixed results, and most are conducted in coastal cities (Gascon et al., 2017). Blue space is hypothesized to support mental health through similar pathways proposed for greenspace (Gascon et al., 2017). However, the effects of blue space are confirmed by very few studies in Chinese cities and most are conducted in older adults (Chen and Yuan, 2020; Garret et al., 2019; Helbich et al., 2019). It is still unknown how blue space will associate with both mental illness and SWB in the general urban Chinese population.
The heterogeneity in associations between nature exposure and mental health among population subgroups mandates further research (Gascon et al., 2015, 2018; Ruijsbroek et al., 2017). Several studies included stratified analysis according to socio-demographic factors (e.g., gender, life stage, ethnicity, socioeconomic status, etc.) and reported mixed findings (further elaborated in Section 2). Empirical evidence has not clarified whether exposure to nature benefits certain population subgroups more than others because of inconsistent evidence across studies (Gascon et al., 2015, 2018). However, accounting for the heterogeneity in subgroup populations is important to target potential beneficiaries and maximize the returns of policy interventions. To our knowledge, these varied associations are not explored in Chinese cities yet, although some studies focus on certain population groups such as older adults (Helbich et al., 2019) and college student (Yang et al., 2019).

To address the aforementioned questions, we conducted a crosssectional study in Guangzhou. Previous studies have examined the relationships between NDVI, street greenery and mental health in Guangzhou, which provided useful insights (Liu et al., 2019, 2020; Wang et al., 2019, 2020). However, the effects of parks and blue space on multiple mental health components, and their heterogeneity in subgroup populations remain unassessed. We attempt to answer the following questions: i) does exposure to urban parks and blue space have equivalent associations with multiple components of mental health? ii) do these associations vary across gender and socioeconomic groups?

\section{Literature review}

Multiple reviews synthesizing progress on the association between nature and mental health have been published in the last decade (Callaghan et al., 2020; Douglus et al., 2017; Gascon et al., 2015, 2017; Houlden et al., 2019; Shuvo et al., 2020; WHO, 2016). We compiled 98 studies from five recent reviews and additional 8 studies in Chinese cities and analyzed the mental health outcomes, population subgroups studied, green/blue space exposure and the main results (Table A.1 in Appendix). A wide spectrum of mental health outcomes were assessed, among which about $30 \%$ of studies assessed specific mental illness including depression (Cohen-Cline et al., 2015), behavioral problems (Markevych et al., 2014), anxiety (Shuvo et al., 2020), mental disorder symptoms (Nutsford et al., 2013), or risk factor of mental illness (Bratman et al., 2015). Mental illness is assessed by validated tools such as K10 (Kessler Psychological Distress), self-reported symptoms (de Vries et al., 2003), or prescription records (Nutsford et al., 2013). About 30\% of studies assessed general mental health, mostly using GHQ (General Health Questionnaire) or a single item question on perceived general mental health. Scarce studies used valid measurement comprising all-round SWB. WEMWBS (Warwick-Edinburgh Mental Well-being Scale), WHO-5 (WHO well-being index), and PANAS (Positive and Negative Affect Scale) are commonly used SWB assessment tools, among which WEMWBS includes hedonic and eudaimonic well-being, WHO-5 focuses on hedonic well-being and PANAS focuses on affect well-being. A four-item subjective well-being tool (ONS4) suggested by the Office for National Statistics of UK includes four dimensions of SWB and was used in three studies (Houlden et al., 2009; White et al., 2013a, 2017). However, the majority of studies measured one aspect of SWB such as life satisfaction, happiness, or quality of life (Kamitsis and Francis, 2013; White et al., 2013b). Less than half of studies assessed two or more mental health components, most of which focus either on multiple mental illnesses, or some dimensions of SWB. There is no single study that investigated mental illness and comprehensive SWB. Due to the variety of mental health and exposure measurements used, it is impossible to further synthesize these results. 
Therefore, a comprehensive and precise understanding on the associations between nature and multiple dimensions of mental health is still lacking.

Although studies have shown mental health benefits from nature in a variety of populations, many studies also showed divergent associations dependent on demographic factors, including gender, age, ethnicity, and socioeconomic status (WHO, 2016). Multiple studies found that females are more likely to benefit from nature than males. Bjork et al. (2008), Reklaitiene et al. (2014) and (Van den Bosch et al. 2015) only found beneficial effects for women. McEachan et al. (2016) found protective effects of nature on depression in pregnant women, especially in the disadvantaged population. However, there are also notable exceptions with opposite findings that beneficial effects are stronger for men (Markevych et al., 2014; Triguero-Maset et al., 2017).

Multiple studies found that individuals from lower socioeconomic positions are more inclined to benefit from nearby greenspace, alleviating the adverse effects of poverty and reducing health disparities - the so-called "equigenic" effect (Frumkin et al., 2017; Mitchell and Popham 2007, 2008; Mitchell et al., 2015). However, a review on low-middle income countries suggested that socioeconomically advantaged communities benefited more from urban greenspace probably modified by better access to greenspace and physical activity (Shuvo et al., 2020). Literature generally endorses the view that urban greenspace promotes mental health across the life course (Douglas et al., 2017). Gascon et al. (2015) concluded that there is some, yet limited, evidence for a positive relationship between greenness and mental health in adults, whereas the evidence was inadequate in children. In addition, ethnicity (McEachan et al., 2018), urbanization level (de Vries et al., 2003), and population density (Ambrey, 2016) are found to modify the association between nature exposure and mental health.

Research on the mental health benefits of nature is a recent interest in China (Liu et al., 2017a; Wang et al., 2020). Most studies on Chinese cities explored the effects of nearby greenspace using cumulative opportunity measures such as NDVI, street view, greenspace within 1 or $1.5 \mathrm{~km}$ buffer. Residential greenness is found to improve mental health through physical activities and social interaction (Liu et al., 2019), while street greenery benefits mental health by additional pathways including reduced air pollution, noise reduction, and stress relief (Wang et al., 2019). The effects of blue space on mental health are rarely assessed and most are conducted among older adults. One study investigated the association between general mental health and blue space area within a $1.5 \mathrm{~km}$ buffer without considering SWB (Liu et al., 2020). Most studies concerning Chinese cities consistently support positive associations between nature exposure and mental health, however, the evidence base is small and additional research remains critical given the narrow range of nature exposure and mental health components examined. Green/blue space proximity and size are rarely considered and limited mental health components are assessed, generally, either a general mental health metric (mostly GHQ-12) or hedonic well-being (mostly WHO-5) are applied (Garrett et al., 2019; Liu et al., 2020). We found no studies investigating the diversity of nature's benefits on mental health in multiple population subgroups, which is another gap that requires further research.

\section{Material and methods}

\subsection{Survey design}

We conducted a mixed mode cross-sectional survey in Guangzhou which combines online and face-to-face surveys to reduce noncoverage and nonresponse error. The online survey was conducted in July and August in 2018 by Wenjuanxing, a survey company that has experience investigating mental health of the Chinese population (https://www.wjx.cn/, Li et al., 2020). We followed the key steps for conducting valid and meaningful online survey as identified by Regmi et al. (2016): (1) user-friendly design and layout; (2) selecting survey participants; (3) avoiding multiple responses; and (4) a pilot study. For steps 1 and 4, we conducted a paper survey with 30 participants, including people of different ages and educational backgrounds, and invited them to comment on the readability of the questionnaire and ordering of the questions. We also did a pilot of 147 online samples to ensure the feasibility of the technology, data transfer, etc. Selecting survey participation (step 2) is important for collecting valid data. Everyday there are on average 1000,000 people responding to surveys, exams, and votes conducted on Wenjuanxing. Wejuanxing invites these people to provide demographic information (age, gender etc.) and join in their sample database. To make sure the participants are real and unduplicated, Wenjuanxing created an account for every member in their sample database which is tied to the phone number, Wechat, or Alipay of the member. Currently, it has a sample database of 2,600,000 people, comprising diverse occupations, age, wealth statuses, hobbies, etc., which constitutes the sample frame for a survey (for the structure of the sample database see https://www.wjx.cn/). Wenjuanxing randomly invites participants in the sample database to complete the survey for financial compensation. To avoid duplicated response due to the incentives (Step 3), the link of the questionnaire became invalid once a response was submitted. Three steps were applied to control the quality of the questionnaire: (1) We deleted questionnaires completed in less than 3 min (2) Trap questions (e.g., let the respondent choose the answer "Agree" in options such as "Disagree", "Strongly agree", "Neutral" etc.); were set to check the attention respondents were paying; (3) We manually excluded other invalid samples such as incomplete questionnaires and questionnaire that had logic contradictions. We collected 933 samples of which $62 \%$ were women and only $10 \%$ of the sample was over 40 years old.

We applied a face-to-face survey among men and elderly adults who were underrepresented in the online survey from August 20th to September 8th, 2020. We took a stratified sampling technique and selected 23 residential communities (xiaoqu) according to house price and neighborhood greenness. We checked 6,654 residential community information (house price, location etc.) from fangtianxia, a leading online real estate portal in China. A residential community with higher than average house prices was defined as "high price" and a residential community with below-average house prices was defined as "low price". We calculated the NDVI in a $500 \mathrm{~m}$ buffer around each residential community to represent the neighborhood greenness level. A residential community with higher NDVI than the average is defined as "high greenness" and a residential community with lower NDVI than the average is defined as "low greenness". Finally, we selected 23 residential communities according to house price and neighborhood greenness level: 6 in the low price and low greenness category (referred to as low-low), 5 with low house prices and high greenness (low-high), 7 of highlow, and 5 of high-high (Table A2 in Appendix). Respondents in these communities were randomly invited to complete the questionnaire with a 2-3 US \$ worth of gift. To reduce measurement errors associated with two different survey modes the questionnaires used in the online and face-to-face surveys were identical.

\subsection{Depression risk and SWB outcomes}

We employed the widely used Mental Health Inventory (MHI5 ), to investigate the population's depressive symptoms (Cuijpers 
et al., 2009). MHI-5 asks the frequency of five situations in the past month: (i) you have been a very nervous person, (ii) felt downhearted and blue, (iii) felt calm and peaceful, (iv) felt so down in the dumps that nothing could cheer you up, and ( $\mathrm{v}$ ) been a happy person. The questions could be answered on a 6-point Likert scale: from 1 (all of the time) to 6 (none of the time). The scoring of positive feelings-items (iii) and (v)-was inversed and summed with the scores from other questions. The mean score of the five items are transformed into a 100 -point scale.

We followed the four-item construct used by the Office for National Statistics of the UK to evaluate SWB (Coldwell and Evans, 2018; White et al., 2017). Four components of well-being were measured: evaluative, eudemonic, positive, and negative affect well-being. For the evaluative well-being, we asked, "Overall, how satisfied are you with your life?" on a scale from 1 (not satisfied at all) to 10 (very satisfied). For eudemonic well-being, we asked, "Overall, to what extent do you feel that the things you do in your life are worthwhile?" on a scale from 1 (not worthwhile at all) to 10 (very worthwhile). For positive and negative affect well-being, we asked, "Overall, how happy did you feel yesterday?" on a scale from 1 (not happy at all) to 10 (very happy), and "Overall, how anxious did you feel yesterday?" on a scale from 1 (not anxious at all) to 10 (very anxious). Similar to the MHI-5 score, we inversed negative measures and converted scores into a 0-100 scale, with higher scores indicating better SWB.

\subsection{Urban park and blue space exposure}

Park exposure is measured by the nearest park area and road network distance to the nearest park. Urban park data were obtained from the Bureau of Forestry and Landscaping of Guangzhou Municipality (http://lyylj.gz.gov.cn/). 211 parks were included. Road network data were obtained from Open Street Map (https:// download.geofabrik.de/). For the online survey, residents' home locations were obtained by asking respondents to point their residence on an interactive map. For the face-to-face survey, the locations of the residential communities are identified in Gaode map (https://www.amap.com/). Then, residents' home locations, the park layer, and the road layer were analyzed in Network Analysis tool in ArcGIS to identify the network distance to the nearest park.

Blue space includes reservoirs, rivers, water, and wetlands. Spatial information was obtained from the Open Street Map (https://download.geofabrik.de/). In line with prior literature (Dzhambov et al., 2018), we calculated the water area within $300 \mathrm{~m}$, $500 \mathrm{~m}$, and $1000 \mathrm{~m}$ buffers from residents' homes. We measured the Euclidian distance from respondents' homes to the nearest water body.

\subsection{Demographic and socioeconomic covariates}

We recorded participants' gender, age, education, income, occupation, marital status, and residence location which have been identified in the literature as confounders impacting the association between nature and mental health (Gascon et al., 2018). In Guangzhou, five districts-Liwan, Yuexiu, Haizhu, Tianhe, and Baiyun-are considered as central urban areas, while the rest are considered as peripheral urban areas. They differ in population density, economic development, and urbanization level. We generated a variable (residence location) representing if respondents lived in central or peripheral areas. Since mental health is impacted by life events (van den Berg et al., 2010), we further included one item in the survey to assess recent life events in the survey by asking, "Have you lately experienced a stressful life event, such as death/illness of family, lost job, sickness, breaking of an intimate relationship, etc.?"

\subsection{Statistics}

A mixed mode survey has the advantage of reducing the total survey error at an affordable cost. However, a combination of different survey modes in one study may lead to different errors due to mode effects. The mode effects include two major components. The first component is mode (self) selection effects, i.e., some population may prefer certain survey type, thus, different modes are associated with different noncoverage and nonresponse errors. Following de Leeuw et al., 2018, we controlled all possible demographic variables (gender, age, education, occupation, income, district of residence, marriage status) to adjust mode selection effects. The second component is mode measurement effects, i.e., different modes produce different observation errors. We added a dummy variable indicating survey mode to adjust measurement error.

Quadratic and cubic terms were tested for a potential nonlinear relationship between the park and blue space exposure and mental health outcomes. Since no significant association were observed, we applied linear regression analysis. We constructed regressions for parks and blue space separately. For blue space, we analyzed $300 \mathrm{~m}, 500 \mathrm{~m}$, and $1000 \mathrm{~m}$ buffers separately. The model for parks and blue space are specified as:

Mental

health $=\beta_{0}+\beta_{1}$ Dummy wave $+\beta_{2}$ NearParkArea $+\beta_{3}$ NetworkDis $+\beta_{4}$ confounders (Eq. 1 for park)

Mental health $=\beta_{0}+\beta_{1}$ Dummy wave $+\beta_{2}$ WaterAreai $+\beta_{3}$ NearWaterDis $+\beta_{4}$ confounders (Eq. 2 for blue space)

Where mental health is MHI-5, life satisfaction, worthwhileness, happy yesterday and anxious yesterday score, respectively. $\beta_{0}$ is the intercept. $\beta_{1}, \beta_{2}, \beta_{3}$, and $\beta_{4}$ are the coefficients. Dummy ${ }_{\text {wave }}$ is 0 for the online survey, and 1 for the face-to-face survey. NearParkArea is the area of the nearest park (unit: ha). NetworkDis is the network distance to the nearest park (unit: meter). Cofounders include gender, age, occupation, education, income, residence location, marital status, life event. WaterAreai is the water area within a certain buffer of residence $(\mathrm{i}=300 \mathrm{~m}, 500 \mathrm{~m}, 1000 \mathrm{~m})$. NearWaterDis is Euclidean distance to the nearest water.

To examine the heterogeneous relationship between nature exposure and mental health, we stratified the sample according to gender, income, and education-which were previously identified as modifiers (Gascon et al., 2015).

As for the robustness check, we randomly excluded $10 \%$ of sample and then conducted a regression with the remaining $90 \%$ sample, controlling all confounders. We repeated this process 500 times and plotted the coefficients of the independent variable subjected to the robustness check for each regression. The full sample regression result is robust if it does not deviate from the results of the 500 regressions with $90 \%$ of sample. All statistical analyses were conducted in Stata 14.

\section{Results}

\subsection{Descriptive statistics}

We collected 1,274 valid questionnaires, with 933 responses in the online survey and 341 responses in the face-to-face survey. Women accounted for $55 \%$ of the sample. People under 20, between 20 and 60 , and over 60 accounted for $17 \%, 75 \%$, and $8 \%$ respectively (Table 1). Respondents with high school or below, junior college, college, or a graduate education accounted for $30 \%, 20 \%, 45 \%$, and $4 \%$ of the population, respectively. Enterprise staff, governmental 
staff, and self-employed accounted for $35 \%, 10 \%$, and $7 \%$ of the sample. About two-thirds (62\%) were married. Two-thirds (70\%) lived in the central area. Half (49\%) earned less than $\$ 750$ per month, $34 \%$ had a monthly income between $\$ 750-1,500$, and $17 \%$ earned more than $\$ 1,500$ per month. The mean ( \pm standard deviation) MHI-5 score of the sample was $63 \pm 14$. The highest SWB component was the "worthwhileness" score $(74 \pm 19)$ and the lowest was the "anxious yesterday" score $(59 \pm 25)$.

\subsection{Full-sample regression}

The nearest park area was significantly associated with MHI-5 ( $p=0.002)$, "worthwhileness" ( $p=0.069$ ), "happy yesterday" $(\mathrm{p}=0.075)$, and "anxious yesterday" scores $(\mathrm{p}=0.052)$ after controlling all confounders (Table 2). Road network distance to the nearest park was not associated with any mental health outcomes.

A water area within $300 \mathrm{~m}$ from respondents' homes was positively associated with MHI-5 ( $p=0.003)$, life satisfaction ( $\mathrm{p}=0.079$ ), and "anxious yesterday" score $(\mathrm{p}=0.09$, Table 2$)$. The water body within $500 \mathrm{~m}$ and $1000 \mathrm{~m}$ buffers were not significantly associated with any mental health outcomes. However, associations between distance to the nearest water and "happy yesterday" and "anxious yesterday" were observed (Table 2, Table A.3 in Appendix).

\subsection{Stratified sample regression}

Stratified regressions by gender showed that access to large parks was positively associated with all SWB indicators among women; Both men and women benefitted from a nearby park in the reduction of depression risk. However, the effects are more significant in women ( $\mathrm{p}=0.022$ for women, and 0.046 for men) and men marginally benefit from access to a nearby park in reducing the "anxious yesterday" score ( $p=0.09$, Table 3$)$. Protective effects on mental health from a nearby blue space were observed only in women (Table 3).

Stratified by income, only in the median-income population was there a significant association between the nearest park area and MHI-5 and "happy yesterday" score (Table 4). Shorter distance to the nearest park also contributed to better MHI-5 scores in the median-income population. Significant improvements in MHI-5, life satisfaction, and "anxious yesterday" scores were found in low-income populations who had access to water within a $300 \mathrm{~m}$ buffer. No protective effect was observed in the high-income groups regardless of whether they were near a larger park or water area (Table 4).

In both low- and high-educated populations, a nearby large park was associated with better MHI-5 scores. However, the nearest park area was associated with "happy yesterday" and "worthwhileness" score only among less-educated respondents. Blue space exposure was correlated with better MHI-5 and all SWB components only in less-educated respondents (Table 5).

\subsection{Robustness checks}

Since the full sample regression showed that the nearest park area and water area within $300 \mathrm{~m}$ buffer are the strongest predictive variables, a robustness check was conducted on these two variables. The results of the robustness check (Fig A.1 in Appendix) are consistent with what is displayed in Table 2. For instance, as shown in the upper-left panel in Fig A.1, most subsample regression coefficients of the nearest park area with MHI-5 were significant ( $\mathrm{p}<0.05$ ), which is consistent with the first column in Table 2.

\section{Discussion}

Our research provides evidence for positive associations between nature exposure and lowers depression risk as well as higher SWB. However, nature contributes distinctly to different aspects of mental health. Both park and blue space exposure had a stronger correlation with lower depression risk (MHI-5) compared with their associations with SWB. Moreover, both park and blue space exposure have significant mitigation effects on short-term negative affect well-being ("anxious yesterday"). However, their associations vary among other SWB components. People who experience negative feelings may unconsciously choose to expose themselves to a restorative environment so that the protective effects are more prominent in mitigating negative emotions. For example, Hartig and Staats (2006) found that mentally fatigued people are inclined to walk in a natural environment rather than in urban settings. Park and blue space exposure associated with different components of SWB. However, achieving improved SWB across all its components requires access to both green and blue space.

Park size (area of the nearest park) is a predictive variable of mental health instead of proximity measures, highlighting the benefits of a larger park. Larger parks often have more facilities and amenities that promote visitation and physical activity, which may generate positive mental health outcomes (Wang et al., 2019).

Table 1

Summary statistics of sampled respondents $(n=1274)$.

\begin{tabular}{|c|c|c|c|c|c|}
\hline Variables & Level & Percent & Variables & Level & Percent/Mean \pm SD \\
\hline \multirow[t]{2}{*}{ Gender } & Female & $55 \%$ & Education & High school or below & $30 \%$ \\
\hline & Male & $45 \%$ & & Junior college & $20 \%$ \\
\hline \multirow[t]{6}{*}{ Age } & under 20 & $17 \%$ & & College & $45 \%$ \\
\hline & $20-30$ & $38 \%$ & & Graduate & $4 \%$ \\
\hline & $30-40$ & $18 \%$ & Marital status & Single & $38 \%$ \\
\hline & $40-50$ & $12 \%$ & & Married & $62 \%$ \\
\hline & $50-60$ & $7 \%$ & District & Inner city & $70 \%$ \\
\hline & over 60 & $8 \%$ & & Peripheral city & $30 \%$ \\
\hline \multirow[t]{9}{*}{ Employment } & Enterprise staff & $35 \%$ & Monthly income & Less than $750 \$$ & $49 \%$ \\
\hline & Governmental institution & $10 \%$ & & $750 \$-1500 \$$ & $34 \%$ \\
\hline & & & & Over $500 \$$ & $17 \%$ \\
\hline & Self-employed & $7 \%$ & MHI-5 score & & $63 \pm 14$ \\
\hline & Freelancers & $12 \%$ & Life satisfaction & & $72 \pm 19$ \\
\hline & Student & $21 \%$ & Worthwhileness & & $74 \pm 19$ \\
\hline & Retiree & $11 \%$ & Happy yesterday & & $73 \pm 22$ \\
\hline & unemployed & $1 \%$ & Anxious yesterday & & $59 \pm 25$ \\
\hline & Other & $3 \%$ & & & \\
\hline
\end{tabular}

Online survey: 933 samples; face-to-face survey: 341 samples. 
Table 2

Associations between the park and blue space exposure and MHI-5 and subjective well-being $(\mathrm{n}=1274)$.

\begin{tabular}{|c|c|c|c|c|c|}
\hline Variables & MHI-5 & Life satisfaction satisfaction & Worthwhileness & Happy yesterday & Anxious yesterday \\
\hline NearParkArea & $\begin{array}{l}\mathbf{0 . 0 0 3} * * * \\
(0.001)\end{array}$ & $\begin{array}{l}0.002 \\
(0.001)\end{array}$ & $\begin{array}{l}\mathbf{0 . 0 0 3 *} \\
(0.001)\end{array}$ & $\begin{array}{l}\mathbf{0 . 0 0 3} * \\
(0.002)\end{array}$ & $\begin{array}{l}\mathbf{0 . 0 0 4} * \\
(0.002)\end{array}$ \\
\hline NetworkDis & $\begin{array}{r}-0.000 \\
(0.000)\end{array}$ & $\begin{array}{l}0.000 \\
(0.000)\end{array}$ & $\begin{array}{r}-0.000 \\
(0.000)\end{array}$ & $\begin{array}{l}-0.000 \\
(0.000)\end{array}$ & $\begin{array}{r}-0.000 \\
(0.000)\end{array}$ \\
\hline $\mathrm{R}^{2}$ & 0.136 & 0.179 & 0.153 & 0.168 & 0.203 \\
\hline WaterArea300m & $\begin{array}{l}\mathbf{0 . 3 2 5} * * \\
(0.149)\end{array}$ & $\begin{array}{l}\text { 0.348* } \\
(0.198)\end{array}$ & $\begin{array}{l}0.268 \\
(0.206)\end{array}$ & $\begin{array}{l}0.374 \\
(0.229)\end{array}$ & $\begin{array}{l}\text { 0.446* } \\
(0.265)\end{array}$ \\
\hline NearWaterDis & $\begin{array}{l}0.000 \\
(0.001)\end{array}$ & $\begin{array}{l}0.000 \\
(0.001)\end{array}$ & $\begin{array}{l}0.000 \\
(0.001)\end{array}$ & $\begin{array}{c}-0.002 \\
(0.001)\end{array}$ & $\begin{array}{l}-\mathbf{0 . 0 0 2} * \\
(0.001)\end{array}$ \\
\hline $\mathrm{R}^{2}$ & 0.133 & 0.180 & 0.152 & 0.170 & 0.206 \\
\hline
\end{tabular}

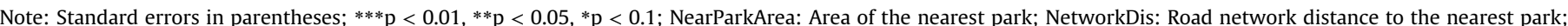

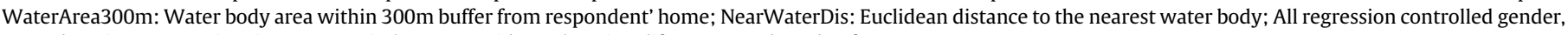
age, education, occupation, income, marital status, residence location, life event, and mode of survey.

Table 3

Stratified associations between park/blue space exposure and MHI-5 and subjective well-being by gender.

\begin{tabular}{|c|c|c|c|c|c|c|c|c|c|c|}
\hline \multirow{2}{*}{ Variables } & \multicolumn{2}{|l|}{ MHI-5 } & \multicolumn{2}{|c|}{ Life satisfaction } & \multicolumn{2}{|c|}{ Worthwhileness } & \multicolumn{2}{|c|}{ Happy yesterday } & \multicolumn{2}{|c|}{ Anxious yesterday } \\
\hline & Female & Male & Female & Male & Female & Male & Female & Male & Female & Male \\
\hline NearParkArea & $\begin{array}{l}\mathbf{0 . 0 0 3} * * \\
(0.001)\end{array}$ & $\begin{array}{l}\mathbf{0 . 0 0 3} * * \\
(0.002)\end{array}$ & $\begin{array}{l}\mathbf{0 . 0 0 4} * * \\
(0.002)\end{array}$ & $\begin{array}{r}-0.001 \\
(0.002)\end{array}$ & $\begin{array}{l}\mathbf{0 . 0 0 4} * * \\
(0.002)\end{array}$ & $\begin{array}{l}0.001 \\
(0.002)\end{array}$ & $\begin{array}{l}\mathbf{0 . 0 0 4 *} \\
(0.002)\end{array}$ & $\begin{array}{l}0.001 \\
(0.003)\end{array}$ & $\begin{array}{l}\mathbf{0 . 0 0 6}^{* *} \\
(0.002)\end{array}$ & $\begin{array}{l}0.000 \\
(0.003)\end{array}$ \\
\hline NetworkDis & $\begin{array}{l}0.000 \\
(0.000)\end{array}$ & $\begin{array}{l}-\mathbf{0 . 0 0 1} \\
(0.000)\end{array}$ & $\begin{array}{l}0.000 \\
(0.000)\end{array}$ & $\begin{array}{l}0.000 \\
(0.000)\end{array}$ & $\begin{array}{l}-0.000 \\
(0.000)\end{array}$ & $\begin{array}{l}0.000 \\
(0.001)\end{array}$ & $\begin{array}{l}-0.000 \\
(0.000)\end{array}$ & $\begin{array}{c}-0.000 \\
(0.001)\end{array}$ & $\begin{array}{l}0.000 \\
(0.000)\end{array}$ & $\begin{array}{l}-\mathbf{0 . 0 0 1} \\
(0.001)\end{array}$ \\
\hline $\mathrm{R}^{2}$ & 0.174 & 0.129 & 0.192 & 0.192 & 0.184 & 0.135 & 0.219 & 0.151 & 0.239 & 0.208 \\
\hline WaterArea300m & $\begin{array}{l}\mathbf{0 . 4 8 6}^{* *} \\
(0.215)\end{array}$ & $\begin{array}{l}0.203 \\
(0.209)\end{array}$ & $\begin{array}{l}\text { 0.641** } \\
(0.276)\end{array}$ & $\begin{array}{l}0.076 \\
(0.291)\end{array}$ & $\begin{array}{l}\mathbf{0 . 8 0 2} * * * \\
(0.292)\end{array}$ & $\begin{array}{l}-0.214 \\
(0.295)\end{array}$ & $\begin{array}{l}\mathbf{0 . 7 8 6}^{* *} \\
(0.327)\end{array}$ & $\begin{array}{c}-0.096 \\
(0.321)\end{array}$ & $\begin{array}{l}0.464 \\
(0.371)\end{array}$ & $\begin{array}{l}0.391 \\
(0.384)\end{array}$ \\
\hline NearWaterDis & $\begin{array}{l}0.000 \\
(0.001)\end{array}$ & $\begin{array}{l}0.000 \\
(0.001)\end{array}$ & $\begin{array}{l}0.001 \\
(0.001)\end{array}$ & $\begin{array}{l}-0.000 \\
(0.002)\end{array}$ & $\begin{array}{l}0.001 \\
(0.001)\end{array}$ & $\begin{array}{l}-0.001 \\
(0.002)\end{array}$ & $\begin{array}{l}-0.001 \\
(0.002)\end{array}$ & $\begin{array}{c}-0.003 \\
(0.002)\end{array}$ & $\begin{array}{l}-0.003 \\
(0.002)\end{array}$ & $\begin{array}{c}-0.002 \\
(0.002)\end{array}$ \\
\hline $\mathrm{R}^{2}$ & 0.174 & 0.122 & 0.192 & 0.192 & 0.188 & 0.136 & 0.224 & 0.154 & 0.238 & 0.207 \\
\hline Observations & 710 & 564 & 710 & 566 & 710 & 566 & 710 & 566 & 710 & 566 \\
\hline
\end{tabular}

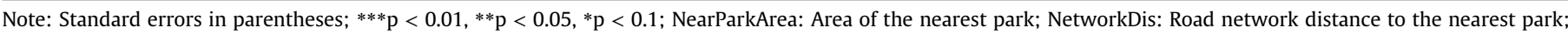

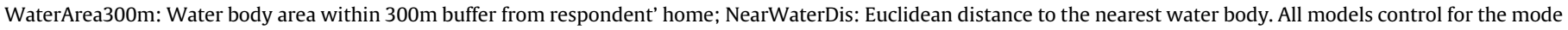
of survey, age, education, occupation, income, marital status, residence location, and life event.

Table 4

Stratified associations between park/blue space exposure and MHI-5 and subjective well-being by income.

\begin{tabular}{|c|c|c|c|c|c|c|c|c|c|c|c|c|c|c|c|}
\hline \multirow[t]{2}{*}{ Variables } & \multicolumn{3}{|l|}{ MHI-5 } & \multicolumn{3}{|c|}{ Life satisfaction } & \multicolumn{3}{|c|}{ Worthwhileness } & \multicolumn{3}{|c|}{ Happy yesterday } & \multicolumn{3}{|c|}{ Anxious yesterday } \\
\hline & Low & Median & High & Low & Median & High & Low & Median & High & Low & Median & High & Low & Median & High \\
\hline NearParkArea & $\begin{array}{l}0.002 \\
(0.001)\end{array}$ & $\begin{array}{l}\mathbf{0 . 0 0 5} * * * \\
(0.002)\end{array}$ & $\begin{array}{l}0.003 \\
(0.003)\end{array}$ & $\begin{array}{l}0.002 \\
(0.002)\end{array}$ & $\begin{array}{l}-0.000 \\
(0.002)\end{array}$ & $\begin{array}{l}0.004 \\
(0.005)\end{array}$ & $\begin{array}{l}0.002 \\
(0.002)\end{array}$ & $\begin{array}{l}0.001 \\
(0.002)\end{array}$ & $\begin{array}{l}0.007 \\
(0.005)\end{array}$ & $\begin{array}{l}0.001 \\
(0.002)\end{array}$ & $\begin{array}{l}\mathbf{0 . 0 0 5} * \\
(0.003)\end{array}$ & $\begin{array}{l}0.003 \\
(0.005)\end{array}$ & $\begin{array}{l}0.002 \\
(0.002)\end{array}$ & $\begin{array}{l}0.005 \\
(0.003)\end{array}$ & $\begin{array}{l}0.004 \\
(0.007)\end{array}$ \\
\hline NetworkDis & $\begin{array}{l}0.000 \\
(0.000)\end{array}$ & $\begin{array}{l}-\mathbf{0 . 0 0 1} * * \\
(0.000)\end{array}$ & $\begin{array}{l}-0.001 \\
(0.001)\end{array}$ & $\begin{array}{l}-0.000 \\
(0.000)\end{array}$ & $\begin{array}{l}0.000 \\
(0.000)\end{array}$ & $\begin{array}{r}-0.000 \\
(0.001)\end{array}$ & $\begin{array}{l}0.000 \\
(0.000)\end{array}$ & $\begin{array}{l}-0.000 \\
(0.000)\end{array}$ & $\begin{array}{l}-0.000 \\
(0.001)\end{array}$ & $\begin{array}{r}-0.000 \\
(0.000)\end{array}$ & $\begin{array}{l}0.000 \\
(0.001)\end{array}$ & $\begin{array}{r}-0.000 \\
(0.001)\end{array}$ & $\begin{array}{l}-0.000 \\
(0.001)\end{array}$ & $\begin{array}{l}-0.001 \\
(0.001)\end{array}$ & $\begin{array}{l}-0.001 \\
(0.002)\end{array}$ \\
\hline $\mathrm{R}^{2}$ & 0.193 & 0.143 & 0.131 & 0.176 & 0.148 & 0.259 & 0.150 & 0.127 & 0.207 & 0.202 & 0.133 & 0.202 & 0.277 & 0.183 & 0.187 \\
\hline WaterArea300m & $\begin{array}{l}\mathbf{0 . 4 5 2} * * \\
(0.196)\end{array}$ & $\begin{array}{l}0.350 \\
(0.265)\end{array}$ & $\begin{array}{l}-0.482 \\
(0.504)\end{array}$ & $\begin{array}{l}\text { 0.448* } \\
(0.264)\end{array}$ & $\begin{array}{l}0.106 \\
(0.353)\end{array}$ & $\begin{array}{l}0.222 \\
(0.671)\end{array}$ & $\begin{array}{l}0.249 \\
(0.275)\end{array}$ & $\begin{array}{l}0.117 \\
(0.365)\end{array}$ & $\begin{array}{l}0.382 \\
(0.688)\end{array}$ & $\begin{array}{l}0.460 \\
(0.303)\end{array}$ & $\begin{array}{l}0.198 \\
(0.400)\end{array}$ & $\begin{array}{l}0.636 \\
(0.808)\end{array}$ & $\begin{array}{l}\mathbf{0 . 6 8 7} * * \\
(0.333)\end{array}$ & $\begin{array}{l}-0.256 \\
(0.480)\end{array}$ & $\begin{array}{l}0.968 \\
(0.969)\end{array}$ \\
\hline NearWaterDis & $\begin{array}{l}-0.000 \\
(0.001)\end{array}$ & $\begin{array}{l}0.001 \\
(0.001)\end{array}$ & $\begin{array}{c}-0.001 \\
(0.003)\end{array}$ & $\begin{array}{l}-0.000 \\
(0.001)\end{array}$ & $\begin{array}{l}-0.000 \\
(0.002)\end{array}$ & $\begin{array}{l}0.001 \\
(0.004)\end{array}$ & $\begin{array}{l}0.000 \\
(0.002)\end{array}$ & $\begin{array}{l}-0.000 \\
(0.002)\end{array}$ & $\begin{array}{l}-0.001 \\
(0.004)\end{array}$ & $\begin{array}{c}-0.002 \\
(0.002)\end{array}$ & $\begin{array}{l}-0.001 \\
(0.002)\end{array}$ & $\begin{array}{c}-0.003 \\
(0.004)\end{array}$ & $\begin{array}{l}-0.002 \\
(0.002)\end{array}$ & $\begin{array}{l}-0.004 \\
(0.003)\end{array}$ & $\begin{array}{l}-0.006 \\
(0.005)\end{array}$ \\
\hline $\mathrm{R}^{2}$ & 0.199 & 0.124 & 0.129 & 0.178 & 0.148 & 0.255 & 0.150 & 0.127 & 0.200 & 0.210 & 0.127 & 0.208 & 0.287 & 0.179 & 0.201 \\
\hline Observations & 628 & 433 & 213 & 629 & 434 & 213 & 629 & 434 & 213 & 629 & 434 & 213 & 629 & 434 & 213 \\
\hline
\end{tabular}

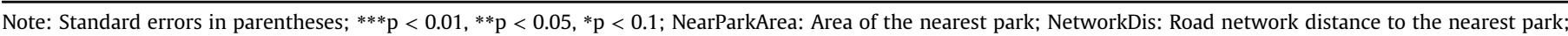

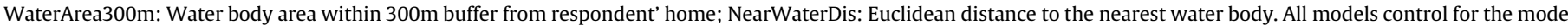

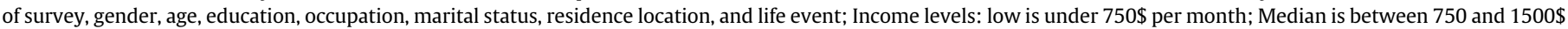
per month; high is above $1500 \$$ per month.

However, this relationship should be tested in other cities, best with pathway analysis since park size may be relevant for certain pathways that mitigate the association between greenspace and mental health, such as physical activity. It may not impact other pathways such as social cohesion, stress reduction, and attention restoration (Ekkel and de Vries, 2017).

Our study observed consistent multiple benefits from exposure to inland blue space, with even larger effect size than parks: a 1-ha increase of blue space within $300 \mathrm{~m}$ of a residents' home will improve the MHI- 5 score by $0.33 \%$, and the negative affect score by
$0.45 \%$. However, this high value of blue space may not be generalized to coastal cities, as coastal ecosystems are perceived as being more attractive than inland water (White et al., 2013c), which may result in lower appreciation for inland water. A study in Catalonia, a coastal region in Spain, did not find a positive association between blue space and mental health (Triguero-Mas et al., 2015). The role of the cumulative area indicator (water area within a certain buffer) becomes non-significant when the buffer exceeds 300m. However, this positive association holds within larger buffers in other studies. For example, de Vries et al. (2003) and de Vries et al. (2016) found 
Table 5

Stratified associations between park/blue space exposure and MHI-5 and subjective well-being by education.

\begin{tabular}{|c|c|c|c|c|c|c|c|c|c|c|}
\hline \multirow[t]{2}{*}{ Variables } & \multicolumn{2}{|l|}{ MHI-5 } & \multicolumn{2}{|c|}{ Life satisfaction } & \multicolumn{2}{|c|}{ Worthwhileness } & \multicolumn{2}{|c|}{ Happy yesterday } & \multicolumn{2}{|c|}{ Anxious yesterday } \\
\hline & Lower & Higher & Lower & Higher & Lower & Higher & Lower & Higher & Lower & Higher \\
\hline NearParkArea & $\begin{array}{l}\mathbf{0 . 0 0 4} * * \\
(0.002)\end{array}$ & $\begin{array}{l}\text { 0.003** } \\
(0.001)\end{array}$ & $\begin{array}{l}0.003 \\
(0.003)\end{array}$ & $\begin{array}{l}0.002 \\
(0.002)\end{array}$ & $\begin{array}{l}\text { 0.005* } \\
(0.003)\end{array}$ & $\begin{array}{l}0.002 \\
(0.002)\end{array}$ & $\begin{array}{l}\mathbf{0 . 0 0 7 * *} \\
(0.003)\end{array}$ & $\begin{array}{l}0.002 \\
(0.002)\end{array}$ & $\begin{array}{l}0.004 \\
(0.003)\end{array}$ & $\begin{array}{l}0.003 \\
(0.002)\end{array}$ \\
\hline NetworkDis & $\begin{array}{l}-0.000 \\
(0.000)\end{array}$ & $\begin{array}{l}-0.000 \\
(0.000)\end{array}$ & $\begin{array}{l}0.000 \\
(0.000)\end{array}$ & $\begin{array}{l}-0.000 \\
(0.000)\end{array}$ & $\begin{array}{l}0.000 \\
(0.000)\end{array}$ & $\begin{array}{l}-0.000 \\
(0.000)\end{array}$ & $\begin{array}{l}0.000 \\
(0.000)\end{array}$ & $\begin{array}{l}-0.001 \\
(0.000)\end{array}$ & $\begin{array}{l}-0.000 \\
(0.001)\end{array}$ & $\begin{array}{l}-0.000 \\
(0.001)\end{array}$ \\
\hline $\mathrm{R}^{2}$ & 0.179 & 0.108 & 0.200 & 0.193 & 0.160 & 0.215 & 0.216 & 0.147 & 0.245 & 0.123 \\
\hline WaterArea $300 \mathrm{~m}$ & $\begin{array}{l}\text { 0.362* } \\
(0.204)\end{array}$ & $\begin{array}{l}0.219 \\
(0.220)\end{array}$ & $\begin{array}{l}\mathbf{0 . 5 9 4} * * \\
(0.278)\end{array}$ & $\begin{array}{l}-0.011 \\
(0.283)\end{array}$ & $\begin{array}{l}\text { 0.517* } \\
(0.287)\end{array}$ & $\begin{array}{c}-0.196 \\
(0.290)\end{array}$ & $\begin{array}{l}\text { 0.584* } \\
(0.308)\end{array}$ & $\begin{array}{l}0.090 \\
(0.345)\end{array}$ & $\begin{array}{l}0.441 \\
(0.349)\end{array}$ & $\begin{array}{l}0.345 \\
(0.410)\end{array}$ \\
\hline NearWaterDis & $\begin{array}{l}-0.000 \\
(0.001)\end{array}$ & $\begin{array}{l}0.001 \\
(0.001)\end{array}$ & $\begin{array}{l}0.000 \\
(0.001)\end{array}$ & $\begin{array}{l}0.001 \\
(0.002)\end{array}$ & $\begin{array}{l}-0.000 \\
(0.002)\end{array}$ & $\begin{array}{l}-0.000 \\
(0.002)\end{array}$ & $\begin{array}{l}-0.001 \\
(0.002)\end{array}$ & $\begin{array}{l}-0.002 \\
(0.002)\end{array}$ & $\begin{array}{l}-\mathbf{0 . 0 0 3} \\
(0.002)\end{array}$ & $\begin{array}{l}-0.001 \\
(0.002)\end{array}$ \\
\hline $\mathrm{R}^{2}$ & 0.177 & 0.100 & 0.203 & 0.191 & 0.161 & 0.214 & 0.216 & 0.147 & 0.252 & 0.123 \\
\hline Observations & 649 & 625 & 650 & 626 & 650 & 626 & 650 & 626 & 650 & 626 \\
\hline
\end{tabular}

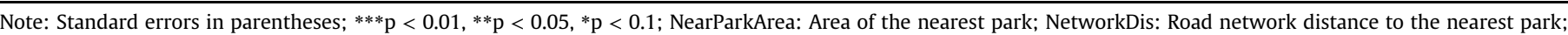

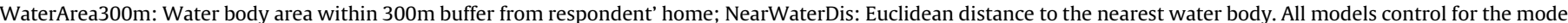

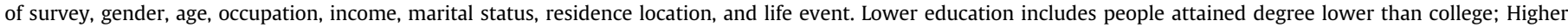
education includes people attained college and graduate degree.

the amount of blue space within $3 \mathrm{~km}$ and $1 \mathrm{~km}$ buffer from a postcode centroid are associated with mental health in their respective study. A possible explanation for the difference is that Chinese people are only willing to travel short distances for recreation in nature. For example, (Liu et al., 2017b) found that a road network distance to parks within $500 \mathrm{~m}$ is associated with park use. This low travel distance may be affected by other socioeconomic factors such as low car ownership or limited time for recreation (Liu et al., 2015). Given the multiple benefits observed in this study, blue space is a potential public health resource. Since the Guideline for Sponge City Construction issued by the General Office of the State Council in 2015, there is a national initiative to increase urban wetlands with the primary purpose of urban flood control (http:// www.gov.cn/zhengce/content/2015-10/16/content_10228.htm).

There is a call for high-quality studies to provide robust and actionable information (e.g., dose-response curve) to guide where to build the blue space to maximize the co-benefits. Guangzhou has large water surfaces ( $747 \mathrm{~km}^{2}$ accounting for $10 \%$ of its area) indicating a potentially large but unrecognized mental health value which should be accounted for to justify the cost of blue space conservation practices.

Our study observed evident heterogeneity in the associations between nature exposure and mental health across gender. Women benefit more from nearby nature, which is consistent with previous findings (Gascon et al., 2018; Reklaitiene et al., 2014). The Chinese time-use survey reports that women spend more time purchasing daily goods, sending children to school, and playing with children, while men spend more time on work (Du et al., 2018). We suspect that the different gender roles of men and women may result in additional passive nature exposure for women compared with men. One similar hypothesis is that female homemaker may spend more time in their neighborhoods than working men (Ruijsbroek et al., 2017). Another possible explanation is that the psychophysiological responses between men and women differ. Roe et al. (2013) found that women in less green neighborhoods exhibit cortisol secretion patterns indicating higher exhaustion and stress than men in deprived communities. However, the cortisol secretion of both men and women in greener neighborhoods indicated better emotional regulation. Future research should explore the mechanism for the non-significant relationship in men to make effective interventions (e.g., programming in parks), in addition to providing a sufficient amount of nature.

Low-to-medium income and less-educated population were more susceptible to benefit from nearby nature in this study than their counterparts. This is consistent with previous evidence-contact with nature may disproportionately benefit disadvantaged populations (Mitchell and Popham, 2007, 2008; Mitchell et al., 2015). Lower socioeconomic strata are more susceptible to mental stress and environmental hazards (e.g., noise pollution); thus, the protective effects may be more significant in these populations. For example, Korpela et al. (2008) and Rogerson et al. (2020) found that nature has stronger restorative effects on people experiencing greater emotional stress or stating lower initial mental health levels. In addition, lower socioeconomic strata may have lower mobility and they may spend more time in nearby public greenspace for recreation. Exploring the patterns of disproportionate access among different groups, their preferences, their experience of nature, and the pattern of benefits across socioeconomic groups and life course is essential to understand the diversity of the relationships between nature and mental health, and create effective interventions (Frumkin et al., 2017). Our crosssectional evidence supports the need to promote greenspace programs in more deprived areas to maximize the returns of green investment, as well as reducing health inequity.

One strength of the present research is that we evaluated multiple mental health outcomes including the depression risk as well as four facets of SWB. This allowed for examination of specific components of mental health that nature exposure associates with. Protective effects were found in most mental health outcomes after controlling for confounders, which provided stronger evidence than single mental health measures. Secondly, our study examined the association of blue space with multiple mental health components which has been rarely assessed in the general Chinese population. Thirdly, we found consistent heterogeneous associations between nature exposure and all five mental health outcomes among population subgroups which was not explored in Chinese cities yet.

However, this study has some limitations. The relationship between nature and mental health is complex. Pathways that could mediate the relationship are not included and causality cannot be inferred in this study. High-quality evidence is lacking in developing countries and it requires long-term prospective or population-level experimental studies to provide robust science to guide practice (Shuvo et al., 2020). Moreover, our study only considered proximity and quantity of urban parks and blue space. Studies on different types (residential greenspace, street trees) and qualities of nature, types (nature view, visitation of different greenspace) and dose of natural exposure (physical activity, socializing, etc.) will provide more precise understanding for urban planning and programming design (Frumkin et al., 2017). Lastly, the 
results found in this study may be confined to big and busy cities such as Guangzhou. Future studies should confirm and clarify these findings in different urban settings, such as medium and small cities, or coastal cities.

\section{Conclusion}

Empirical evidence concerning the degree to which nature might enhance mental health is required in Chinese cities to promote effective interventions in urban planning and management. We examined the associations between park/blue space exposure and multiple aspects of mental health and its heterogeneity in population subgroups in the Chinese city of Guangzhou. We have three main conclusions. First, both park and blue space exposure have protective effects on the population's mental health. Blue space has a larger effect size than parks with a 1-ha increase of blue space associating with $0.45 \%$ increase in mental health scores. Given the dense population in Guangzhou, the aggregate benefits at the population level could be substantial. Second, nature exposure associates differently with specific components of mental health. Park and blue space exposure were more consistently associated with lower depression risks and negative affect wellbeing. Varied associations were observed with positive affective, evaluative, and eudaimonic well-being. Achieving SWB across all its components requires access to both green and blue space. Third, heterogeneous associations between nature exposure and mental health exist in population subgroups. Compared to their counterparts, women, low-to-medium income, and less-educated population are inclined to gain more mental health benefits from nearby nature. This study highlights the importance of integrating nature's mental health benefits in urban planning and management in Chinese cities. However, such actions need to consider gender and socioeconomic differences to make effective interventions. Promoting nature in more deprived areas may help maximize the returns of green investments, as well as reducing health inequity.

\section{Acknowledgement}

This research was supported by the National Science Foundation for Young Scientists of China (Project No.41801224); Science and Technology Plan Project of Guangzhou (Project No. 201904010159); Key Special Project for Introduced Talents Team of Southern Marine Science and Engineering Guangdong Laboratory (Guangzhou) (Project No. GML2019ZD0408); Science Foundation of Guangdong Province, General Project (Project No. 2018A0303130077); Key Research and Development Program of Guangdong Province (Project No. 2020B1111530004). We especially thank Prof. Hongfang Lu on her very valuable suggestions in the revision process.

\section{CRediT authorship contribution statement}

Hongxiao Liu: Conceptualization, Methodology, Writing original draft, Formal analysis, Writing - review \& editing. Hai Ren: Conceptualization, Methodology, Funding acquisition. Roy P. Remme: Methodology, Writing - review \& editing. Huifu Nong: Conceptualization, Methodology, Resources, Software, Supervision. Chunhua Sui: Formal analysis.

\section{Declaration of competing interest}

The authors declare that they have no known competing financial interests or personal relationships that could have appeared to influence the work reported in this paper.

\section{Appendix A. Supplementary data}

Supplementary data to this article can be found online at https://doi.org/10.1016/j.jclepro.2021.127100.

\section{References}

Amano, T., Butt, I., Peh, K.S.H., 2018. The importance of green spaces to public health: a multi-continental analysis. Ecol. Appl. 28 (6), 1473-1480.

Ambrey, C.L., 2016. Greenspace, physical activity and well-being in Australian capital cities: how does population size moderate the relationship? Publ. Health $133,38-44$.

Björk, J., Albin, M., Grahn, P., Jacobsson, H., Ardö, J., Wadbro, J., Östergren, P.-O., Skärbäck, E., 2008. Recreational values of the natural environment in relation to neighbourhood satisfaction, physical activity, obesity and wellbeing. J. Epidemiol. Community 62 (4) e2-e2.

Bratman, G.N., Hamilton, J.P. Daily, G.C., 2012. The impacts of nature experience on human cognitive function and mental health. Ann. N. Y. Acad. Sci. 1249 (1), 118-136.

Bratman, G.N., Hamilton, J.P., Hahn, K.S., Daily, G.C., Gross, J.J., 2015. Nature experience reduces rumination and subgenual prefrontal cortex activation. Proc. Natl. Acad. Sci. U. S. A 112 (28), 8567-8572.

Callaghan, A., McCombe, G., Harrold, A., McMeel, C., Mills, G., Moore-Cherry, N., Cullen, W., 2020. The impact of green spaces on mental health in urban settings: a scoping review. J. Ment. Health 1-15. https://doi.org/10.1080/ 09638237.2020.1755027.

Chen, Y., Yuan, Y., 2020. The neighborhood effect of exposure to blue space on elderly individuals' mental health: a case study in Guangzhou, China. Health Place 63.

Cohen-Cline, H., Turkheimer, E., Duncan, G.E., 2015. Access to green space, physical activity and mental health: a twin study. J. Epidemiol. Community Health 69 (6), 523-529.

Coldwell, D.F., Evans, K.L., 2018. Visits to urban green-space and the countryside associate with different components of mental well-being and are better predictors than perceived or actual local urbanization intensity. Landsc. Urban Plann. 175, 114-122.

Cuijpers, P., Smits, N., Donker, T., Ten Have, M., de Graaf, R., 2009. Screening for mood and anxiety disorders with the five-item, the three-item, and the twoitem Mental Health Inventory. Psychiatr. Res. 168 (3), 250-255.

de Leeuw, E., Suzer-Gurtekin, T., Hox, J., 2018. The Design and Implementation of Mixed-mode Surveys. Advances in Comparative Survey Methods: Multinational, Multiregional, and Multicultural Contexts (3MC) 387-409.

de Vries, S., ten Have, M., van Dorsselaer, S., van Wezep, M., Hermans, T., de Graaf, R., 2016. Local availability of green and blue space and prevalence of common mental disorders in The Netherlands. BJPsych Open 2 (6), 366-372.

de Vries, S., Verheij, R.A., Groenewegen, P.P., Spreeuwenberg, P., 2003. Natural environments-healthy environments? An exploratory analysis of the relationship between greenspace and health. Environ. Plann. 35 (10), 1717-1731.

Douglas, O., Lennon, M., Scott, M., 2017. Green space benefits for health and wellbeing: a life-course approach for urban planning, design and management. Cities 66, 53-62.

Du, F.L., Wang, W.B., Dong, X.Y. (Eds.), 2018. Where Has Time Gone? Research Report of Chinese Time Use Survey. China Social Sciences Press, Beijing.

Dzhambov, A.M., Markevych, I., Hartig, T., Tilov, B., Arabadzhiev, Z., Stoyanov, D. Gatseva, P., Dimitrova, D.D., 2018. Multiple pathways link urban green- and bluespace to mental health in young adults. Environ. Res. 166, 223-233.

Ekkel, E.D., de Vries, S., 2017. Nearby green space and human health: evaluating accessibility metrics. Landsc. Urban Plann. 157, 214-220.

Frumkin, H., Bratman, G.N., Breslow, S.J., Cochran, B., Kahn Jr., P.H., Lawler, J.J. Levin, P.S., Tandon, P.S., Varanasi, U., Wolf, K.L., Wood, S.A., 2017. Nature contact and human health: a research agenda. Environ. Health Perspect. 125 (7).

Fu, X.L., Zhang, K. (Eds.), 2019. Report on National Mental Health Development in China (2017-2018). Social Sciences Academic Press (China), Beijing.

Garrett, J.K., White, M.P., Huang, J., Ng, S., Hui, Z., Leung, C., Tse, L.A., Fung, F., Elliott, L.R., Depledge, M.H., Wong, M.C.S., 2019. Urban blue space and health and wellbeing in Hong Kong: results from a survey of older adults. Health Place $55,100-110$.

Gascon, M., Sánchez-Benavides, G., Dadvand, P., Martínez, D., Gramunt, N., Gotsens, X., Cirach, M., Vert, C., Molinuevo, J.L., Crous-Bou, M. Nieuwenhuijsen, M., 2018. Long-term exposure to residential green and blue spaces and anxiety and depression in adults: a cross-sectional study. Environ. Res. 162, 231-239.

Gascon, M., Triguero-Mas, M., Martinez, D., Dadvand, P., Forns, J., Plasencia, A. Nieuwenhuijsen, M.J., 2015. Mental health benefits of long-term exposure to residential green and blue spaces: a systematic review. Int. J. Environ. Res. Publ. Health 12 (4), 4354-4379.

Gascon, M., Zijlema, W., Vert, C., White, M.P. Nieuwenhuijsen, MJ., 2017. Outdoor blue spaces, human health and well-being: a systematic review of quantitative studies. Int. J. Hyg Environ. Health 220 (8), 1207-1221.

Hartig, T., Mitchell, R., Vries, S.d., Frumkin, H., 2014. Nature and health. Annu. Rev. Publ. Health 35 (1), 207-228.

Hartig, T., Staats, H., 2006. The need for psychological restoration as a determinant of environmental preferences. J. Environ. Psychol. 26 (3), 215-226. 
Helbich, M., Yao, Y., Liu, Y., Zhang, J., Liu, P., Wang, R., 2019. Using deep learning to examine street view green and blue spaces and their associations with geriatric depression in Beijing, China. Environ. Int. 126, 107-117.

Houlden, V., Porto de Albuquerque, J., Weich, S., Jarvis, S., 2019. A spatial analysis of proximate greenspace and mental wellbeing in London. Appl. Geogr. 109, 102036.

Kahneman, D., Diener, E., Schwarz, N. (Eds.), 1999. Well-Being: Foundations of Hedonic Psychology. Russell Sage Foundation.

Kamitsis, I., Francis, A.J., 2013. Spirituality mediates the relationship between engagement with nature and psychological wellbeing. J. Environ. Psychol. 36, $136-143$.

Keyes, C.L.M., 2006. Subjective well-being in mental health and human development research worldwide: an introduction. Soc. Indicat. Res. 77 (1), 1-10.

Korpela, K.M., Ylén, M., Tyrvainen, L., Silvennoinen, H., 2008. Determinants of restorative experiences in everyday favourite places. Health Place 14 (4), 636-652.

Li, J., Yang, Z., Qiu, H., Wang, Y., Jian, L., Ji, J., Li, K., 2020. Anxiety and depression among general population in China at the peak of the COVID-19 epidemic. World Psychiatr. 19 (2), 249.

Liu, H., Li, F., Li, J., Zhang, Y., 2017a. The relationships between urban parks, residents' physical activity, and mental health benefits: a case study from Beijing, China. J. Environ. Manag. 190, 223-230.

Liu, H.X., Li, F., Xu, L.F., Han, B.L., 2017b. The impact of socio-demographic, environmental, and individual factors on urban park visitation in Beijing, China. J. Clean. Produ. 163, S181-S188.

Liu, Y., Wang, R., Grekousis, G., Liu, Y., Yuan, Y., Li, Z., 2019. Neighborhood greenness and mental wellbeing in Guangzhou, China: what are the pathways? Landsc. Urban Plann. 190, 103602.

Liu, Y., Wang, R., Lu, Y., Li, Z., Chen, H., Cao, M., Zhang, Y., Song, Y., 2020. Natural outdoor environment, neighbourhood social cohesion and mental health: using multilevel structural equation modelling, streetscape and remote-sensing metrics. Urban For. Urban Green. 48, 126576.

Markevych, I., Tiesler, C.M.T., Fuertes, E., Romanos, M., Dadvand, P., Nieuwenhuijsen, M.J., Berdel, D., Koletzko, S., Heinrich, J., 2014. Access to urban green spaces and behavioral problems in children: results from the GINIplus and LISAplus studies. Environ. Int. 71, 29-35.

McEachan, R., Prady, S., Smith, G., Fairley, L., Cabieses, B., Gidlow, C., Wright, J., Dadvand, P., Van Gent, D., Nieuwenhuijsen, M.J., 2016. The association between green space and depressive symptoms in pregnant women: moderating roles of socioeconomic status and physical activity. J. Epidemiol. Community Health 70 (3), 253-259.

McEachan, R.R., Yang, T.C., Roberts, H., Pickett, K.E., Arseneau-Powell, D., Gidlow, C.J., Wright, J., Nieuwenhuijsen, M., 2018. Availability, use of, and satisfaction with green space, and children's mental wellbeing at age 4 years in a multicultural, deprived, urban area: results from the born in Bradford cohort study. The Lancet Planetary Health 2 (6), e244-e254.

Mitchell, R., Popham, F., 2007. Greenspace, urbanity and health: relationships in England. J. Epidemiol. Community Health 61 (8), 681.

Mitchell, R., Popham, F., 2008. Effect of exposure to natural environment on health inequalities: an observational population study. Lancet 372 (9650), 1655-1660.

Mitchell, R.J., Richardson, E.A., Shortt, N.K., Pearce, J.R., 2015. Neighborhood environments and socioeconomic inequalities in mental well-being. Am. J. Prev. Med. 49 (1), 80-84.

Nutsford, D., Pearson, A.L., Kingham, S., 2013. An ecological study investigating the association between access to urban green space and mental health. Publ. Health 127 (11), 1005-1011.

O’Donnell, G., Deaton, A., Durand, M., Halpern, D., Layard, R., 2014. Wellbeing and Policy. Legatum institute, London.

Regmi, P.R., Waithaka, E., Paudyal, A., Simkhada, P., Van Teijlingen, E., 2016. Guide to the design and application of online questionnaire surveys. Nepal J. Epidemiol. 6 (4), 640, 2016.

Reklaitiene, R., Grazuleviciene, R., Dedele, A., Virviciute, D., Vensloviene, J., Tamosiunas, A., Baceviciene, M., Luksiene, D., Sapranaviciute-Zabazlajeva, L., Radisauskas, R., Bernotiene, G., Bobak, M., Nieuwenhuijsen, M.J., 2014. The relationship of green space, depressive symptoms and perceived general health in urban population. Scand. J. Publ. Health 42 (7), 669-676.

Roe, J., Thompson, C.W., Aspinall, P., Brewer, M.J., Duff, E.I., Miller, D., Mitchell, R.,
Clow, A., 2013. Green space and stress: evidence from cortisol measures in deprived urban communities. Int. J. Environ. Res. Publ. Health 10 (9), 4086-4103.

Rogerson, M., Wood, C., Pretty, J., Schoenmakers, P., Bloomfield, D., Barton, J., 2020. Regular doses of nature: the efficacy of green exercise interventions for mental wellbeing. Int. J. Environ. Res. Publ. Health 17 (5), 1526.

Ruijsbroek, A., Droomers, M., Kruize, H., Van Kempen, E., Gidlow, C., Hurst, G., Andrusaityte, S., Nieuwenhuijsen, M.J., Maas, J., Hardyns, W., 2017. Does the health impact of exposure to neighborhood green space differ between population groups? An explorative study in four European cities. Int. J. Environ. Res. Publ. Health 14 (6), 618.

Shuvo, F.K., Feng, X., Akaraci, S., Astell-Burt, T., 2020. Urban green space and health in low and middle-income countries: a critical review. Urban For. Urban Green. 52,126662 .

Thorsen, S.V., Rugulies, R., Hjarsbech, P.U., Bjorner, J.B., 2013. The predictive value of mental health for long-term sickness absence: the Major Depression Inventory (MDI) and the Mental Health Inventory (MHI-5) compared. BMC Med. Res. Methodol. 13.

Triguero-Mas, M., Dadvand, P., Cirach, M., Martínez, D., Medina, A., Mompart, A., Basagaña, X., Gražulevičienè, R., Nieuwenhuijsen, M.J., 2015. Natural outdoor environments and mental and physical health: relationships and mechanisms. Environ. Int. 77, 35-41.

Triguero-Mas, M., Donaire-Gonzalez, D., Seto, E., Valentín, A., Martínez, D., Smith, G., Hurst, G., Carrasco-Turigas, G., Masterson, D., van den Berg, M., Ambròs, A., Martínez-Íñiguez, T., Dedele, A., Ellis, N., Grazulevicius, T., Voorsmit, M., Cirach, M., Cirac-Claveras, J., Swart, W., Clasquin, E., Ruijsbroek, A., Maas, J., Jerret, M., Gražulevičienė, R., Kruize, H., Gidlow, C.J., Nieuwenhuijsen, M.J., 2017. Natural outdoor environments and mental health: stress as a possible mechanism. Environ. Res. 159, 629-638.

United Nations, Department of Economic and Social Affairs, Population Division, 2019. World Urbanization Prospects: the 2018 Revision (ST/ESA/SER.A/420), United Nations, New York.

van den Berg, A.E., Maas, J., Verheij, R.A., Groenewegen, P.P., 2010. Green space as a buffer between stressful life events and health. Soc. Sci. Med. 70 (8), 1203-1210.

Van den Bosch, M.A., Östergren, P.-O., Grahn, P., Skärbäck, E., Währborg, P., 2015. Moving to serene nature may prevent poor mental health-results from a Swedish longitudinal cohort study. Int. J. Environ. Res. Publ. Health 12 (7), 7974-7989.

Wang, R., Helbich, M., Yao, Y., Zhang, J., Liu, P., Yuan, Y., Liu, Y., 2019. Urban greenery and mental wellbeing in adults: cross-sectional mediation analyses on multiple pathways across different greenery measures. Environ. Res. 176, 108535.

Wang, R., Yang, B., Yao, Y., Bloom, M.S., Feng, Z., Yuan, Y., Zhang, J., Liu, P., Wu, W., Lu, Y., Baranyi, G., Wu, R., Liu, Y., Dong, G., 2020. Residential greenness, air pollution and psychological well-being among urban residents in Guangzhou, China. Sci. Total Environ. 711, 134843.

White, M.P., Alcock, I., Wheeler, B.W., Depledge, M.H., 2013b. Would you Be happier living in a greener urban area? A fixed-effects analysis of panel data. Psychol. Sci. 24 (6), 920-928.

White, M.P., Alcock, I., Wheeler, B.W., Depledge, M.H., 2013c. Coastal proximity, health and well-being: results from a longitudinal panel survey. Health Place 23, $97-103$

White, M.P., Pahl, S., Ashbully, K., Herber, S., Depledge, M.H., 2013a. Feelings of restoration from recent nature visits. J. Environ. Psychol. 35, 40-51.

White, M.P., Pahl, S., Wheeler, B.W., Depledge, M.H., Fleming, L.E., 2017. Natural environments and subjective wellbeing: different types of exposure are associated with different aspects of wellbeing. Health Place 45, 77-84.

Wood, L., Hooper, P., Foster, S., Bull, F., 2017. Public green spaces and positive mental health-investigating the relationship between access, quantity and types of parks and mental wellbeing. Health Place 48, 63-71.

World Health Organization, 2016. Urban Green Spaces and Health. WHO Regional Office for Europe, Copenhagen.

Yang, T., Barnett, R., Fan, Y., Li, L., 2019. The effect of urban green space on uncertainty stress and life stress: a nationwide study of university students in China. Health Place 59.

Zhang, R., Wulff, H., Duan, Y., Wagner, P., 2019. Associations between the physical environment and park-based physical activity: a systematic review. J.Sport. Health.Sci 8 (5), 412-421. 